\title{
The management of neuropathic pain from neuromas in the upper limb: surgical techniques and future directions
}

\author{
Tereze Laing ${ }^{1,2}$, Aftab Siddiqui ${ }^{1,2}$, Manu Sood ${ }^{1,2}$ \\ ${ }^{1}$ Department of Hand Surgery, St. Andrew's Centre for Plastic Surgery and Burns, Broomfield Hospital, Chelmsford, Essex CM4 9QZ, UK. \\ ${ }^{2}$ Department of Plastic Surgery Research, St. Andrew's and Anglia Ruskin Research Unit, Bishop Hall Lane, Chelmsford, Essex CM1 1SQ, UK.
}

Address for correspondence: Ms. Tereze Laing, St. Andrew's Centre for Plastic Surgery and Burns, Broomfield Hospital, Chelmsford, Essex CM4 9QZ, UK. E-mail: terezelaing@yahoo.com

\begin{abstract}
Neuropathic pain of the upper limb results from damage or disease of the upper limb somatosensory system caused by wide range of pathologies including peripheral neuromas. Treatment strategies depend on making an accurate diagnosis, recognizing co-existing pathologies, and formulating an individualized treatment plan that commonly involves multiple modalities. A long list of nonsurgical and surgical methods acting peripherally (neuromodulation, nerve blocks, surgical manipulation of the nerve) and centrally (medications, spinal cord, and deep brain stimulation) has been described and it is clear that no one treatment is wholly reliable. In this article, we briefly review the pathophysiology of pain caused by neuromas, the current treatment options and the latest research in therapeutic developments.
\end{abstract}

Key words:

Nerve, neuroma, neuromodulation, pain, relocation

\section{INTRODUCTION}

The international association for the study of pain defines neuropathic pain as pain resulting from a lesion or disease in the central or peripheral nervous system. ${ }^{[1-3]}$ This categorization is broad and includes a range of etiologies such as trauma, lesions of the central nervous system, diabetic peripheral neuropathy, multiple sclerosis, and herpetic nerve lesions. When the upper limb is involved, it also includes chronic nerve compression, neuritis and complex regional pain syndrome. A significant proportion of pain in the upper limb results from neuroma formation. Currently, our knowledge of the underlying mechanisms is limited for pain resulting from complex regional pain syndrome and diabetic peripheral neuropathy. However,

\begin{tabular}{|l|l|}
\hline \multicolumn{2}{|c|}{ Access this article online } \\
\hline Quick Response Code: & Website: \\
\hline & www.parjournal.net \\
\hline & \\
\hline
\end{tabular}

due to the wealth of research pain secondary to peripheral neuromas is reasonably well-understood.

\section{PATHOPHYSIOLOGY OF THE PERIPHERAL NEUROMA}

A neuroma is formed with when a nerve is transected and is not surgically repaired successfully. The word neuroma means "nerve tumor" and accurately describes the bulbous mass of regenerating axons that grow in an uncoordinated fashion from the proximal nerve end. This tissue consists of Schwann cells, fibroblasts, blood vessels, and regenerating axons. Neuromas may be further defined by the integrity of the nerve components. An end neuroma occurs following complete nerve transection or neurotmesis by Sunderland's classification. The term partial neuroma or neuroma-in-continuity (Sunderland grade 4-6 injury) is used to describe nerves that are partly intact.

Persisting pain arising from a terminal neuroma is relatively uncommon, estimated to occur in $3-5 \%$ of peripheral nerve injuries. ${ }^{[4]}$ In general, complete nerve transections do not result in major pain. Two main processes are believed to be responsible that of persistent abnormal peripheral nerve stimulation and central 
changes in cortical processing of pain. The first is that of persistent stimulation of free nerve endings at the site of injury with pain transmitted via the small diameter $\mathrm{A}$ delta and $\mathrm{C}$ fibers to the central somatosensory cortex..$^{[5]}$ Following nerve injury, the proximal free nerve endings are unmyelinated, and these small diameter fibers have increased electrical activity and are stimulated at lower thresholds. Spontaneous, mechanical and chemical activity has also been demonstrated within the neuroma. This is accompanied by spontaneous activity in neurons of the dorsal root ganglion, dorsal horn and more proximally within the central nervous system. In addition, it is believed that changes in the central processing of the somatosensory cortex result in amplification of the pain response and perpetuation of the pain process even after the injury is treated successfully by surgery. ${ }^{[6]}$

The most severe pain occurs after partial injuries to the nerve trunks or injury to the terminal branches of the smaller cutaneous nerves such as the superficial radial nerve, medial and lateral cutaneous nerves of the forearm, palmar branch of the median nerve and the sural and saphenous nerves of lower limbs. However, surgical removal of these nerves for use as grafts for nerve reconstruction rarely leads to neuropathic pain.

\section{Presentation}

The patient describes sensory symptoms in the distribution of the affected nerve. This is usually accompanied by a history of previous injury or surgery in the vicinity of the nerve. Other pathologies causing neuropathic pain such as nerve compression and complex regional pain syndrome must be ruled out as these conditions can co-exist with a neuroma.

Our unit previously described a simple assessment tool for grading pain from neuromas using characteristic symptoms: (1) baseline pain, (2) spontaneous spikes of pain, (3) pain exerted by pressure over the nerve, (4) pain on movement of the adjacent joints, and (5) cutaneous "hyperesthesia".

Other clinical terms used to describe the pain are: (1) dysesthesia: any abnormal unpleasant sensation; (2) allodynia: pain from a stimulus that is, not normally painful; (3) hyperpathia: exaggerated pain from a normally painful stimulus; (4) hyperesthesia-an abnormal increase in sensitivity to stimuli; and (5) paresthesia: an abnormal sensation typically tingling or prickling "pins and needles". Localization of the symptoms guides the clinician to identify the injured nerve. The range of symptoms varies from complete anesthesia distally (indicating nerve transection) to hyperesthesia or hyperpathia. Palpation of the neuroma bulb results in tenderness and light percussion over the nerve elicits paresthesias in the distribution of the nerve.

Neuropathic pain is intractable, severely debilitating, and disproportionately intense in relation to the initiating injury. Alongside sensory disturbances, there may be motor disturbance and abnormal sympathetic responses. In these cases, the distinction between neuroma pain and chronic regional pain syndrome or a severe compressive neuropathy may be difficult and often there are overlapping features. In these situations, electrophysiologic studies and local anesthetic blocks are useful as diagnostic adjuncts. Electromyography and nerve conduction studies will usually establish if there is a compressive element. Neuroma pain is significantly reduced or diminished with infiltration of a small amount of local anesthetic around the nerve proximal to the suspected lesion.

\section{Prevention}

Given the challenges of treating neuroma pain, the importance of prevention must be stressed. Avoidance of nerve injury seems obvious yet cannot be emphasized enough given that iatrogenic injuries are cited as a major etiological source, especially with procedures such as ganglion resection, surgery for De Quervain's syndrome or procedures on ulnar head. ${ }^{.7]}$ It is imperative that once an injury is diagnosed an attempt at primary repair be undertaken as soon as possible. The precise microsurgical coaptation of the epineurium has been shown to reduce the incidence of neuroma formation. ${ }^{[8]}$ Providing the advancing axons are directed appropriately they may reestablish connections with their end-organs thereby restoring function in terms of muscle innervation and sensibility. If a nerve is found to be in-continuity, it is advised to perform an external neurolysis and to initiate early mobilization after surgery.

\section{TREATMENT STRATEGIES}

\section{Nonsurgical therapies}

It is difficult to treat pain from neuroma, and a wide range of surgical and nonsurgical therapies have been described. Analgesia with or without supplementary neuropathic agents should be introduced early and prescribed to be taken regularly following any traumatic nerve injury. Early aggressive medical treatment and preemptive analgesia have both been shown to improve prognosis and reduce pain in upper limb pain conditions. ${ }^{[9,10]}$

Medical management consists of four main classes of oral medication: (1) antidepressants with reuptake blocking effect, (2) anticonvulsants with sodium-blocking action, (3) anticonvulsants with calcium-modulating actions, and (4) opioids.

Topical treatments for patients experiencing cutaneous hyperalgesia and allodynia include capsaicin and local anesthetics administered as slow release patches. In many situations, an early combination of medications working at different levels of the pain pathway by different mechanisms is useful. Current randomized controlled trials provide general pain relief values for specific medications, which may explain the failure to obtain complete pain relief in neuropathic pain. A detailed review of medical therapies for upper limb neuropathic pain is beyond the scope of this article but we would refer readers to the articles in the references. ${ }^{[1-14]}$

\section{Neuromodulation}

Our preferred next step in management is a trial of peripheral external electrical stimulation, also known as 


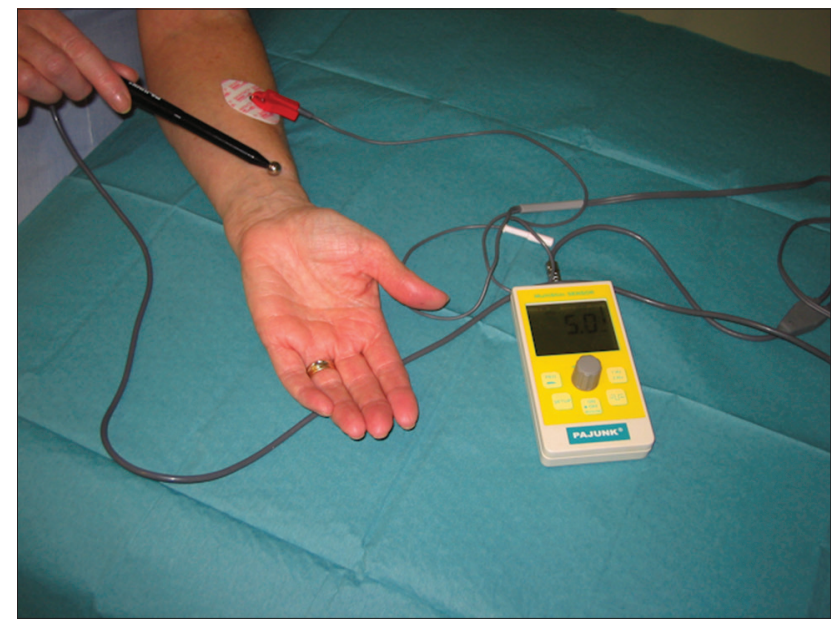

Figure 1: External neuromodulation requires minimal, inexpensive equipment which includes an external neuromodulator, electrocardiogram electrode and stimulating probe

neuromodulation [Figure 1]. This involves the application of an external stimulating probe to the affected nerve proximal to the site of the painful neuroma or over the nerve supplying the area of hypersensitivity for a period of 5-10 min. A low voltage current passes from the generator to the nerve through the skin. There is a paucity of literature relating to the use of neuromodulation in the upper limb. In our series of 102 patients with upper limb pain, greater than $30 \%$ patients experienced complete resolution of pain and $21.5 \%$ patients experienced pain relief lasting from days to weeks and elected for further treatment. ${ }^{[15]}$

This still leaves a proportion of patients whose symptoms persist and who are considered candidates for surgery.

\section{SURGERY FOR END-NEUROMAS}

The surgical options described for management of the terminal neuroma can be broadly classified into the following categories: (a) neuroma resection and reconstruction, (b) simple neuroma resection, (c) containment of the neuroma, and (d) relocation of the nerve into different environments (denervated skin, muscle, bone).

\section{Neuroma resection and reconstruction}

When there is a delay in diagnosis of nerve transection by a few weeks or months, the nerve ends are often retracted, and primary repair of the nerve is not possible. The decision to reconstruct the nerve or nor depends on two main factors: the functional importance of restoring some of the nerve's action and the likelihood of achieving a successful result. The former will be dictated by the nerve involved, the handedness and occupation of the patient; the latter by the patient's age, the time since the initial insult and the level of injury. The decision is made jointly with the patient. Avein, nerve, muscle or synthetic substance can be used for reconstruction. It is our preference to reconstruct small distal digital nerve gaps of less than $2 \mathrm{~cm}$ with posterior interosseous nerve grafts and any larger gaps with sural nerve grafts.

\section{Simple neuroma resection}

Resection of the neuroma alone is the least successful surgical method to treat neuromas of the hand and forearm. ${ }^{[16]}$ However, laboratory studies have revealed that the type of nerve transection can affect neuroma formation. Neuromas developed more often after electrocautery than simple scissors cut or suture ligation and division. ${ }^{[17]}$ Decreased neuroma formation and improved nerve regeneration have been noted with oblique transection in comparison with transverse sectioning for grafting. ${ }^{[18,19]}$ It is suggested that the longer fibers provide a growth pathway for the shorter ones with oblique transection.

\section{Containment}

A number of methods of containment have been described in the literature, but poor results have led this technique to be largely abandoned. The aim of this method is to contain regenerating fascicles within the nerve trunk thereby preventing the proliferation of axonal tissue into the surrounding structures. Although few studies report success with a technique of fascicle resection and ligation of the epineural sleeve, there have been no studies published on the technique since $1989 . .^{[8,20]}$

Other materials have been used in attempts to seal or cap the nerve following neuroma resection. Dahlin and Lundborg ${ }^{[21]}$ and determined a potential role for the use of silicone tubes in peripheral nerve repair, observing in experimental studies a reduced tendency to neuroma formation. However, in the management of end neuromas other clinical studies showed no advantage of silicone capping over simple excisional neurectomy. ${ }^{[8]}$

Other reported methods of containing end neuromas include the formation of end-to-side anastomoses or nerve loops. Experimental studies have demonstrated that by attaching the proximal nerve end-to-side to an adjacent nerve, the neuromas that form are smaller when compared to transection and epineural ligation. ${ }^{[22]}$ However, only preliminary clinical studies using this technique have been reported with small patient numbers. ${ }^{[23,24]}$

The "nerve-loop" procedure, also referred to as "centrocentral nerve union" consists of sequestration of regenerating axons and inhibition of regeneration by suturing one free nerve ending end to end to another. Although there are limited reports of success with this technique, we have no successful experience of its use. ${ }^{[25]}$

\section{Neuroma resection and nerve relocation}

The method of nerve translocation into local muscle or bone was first introduced by Herndon et al. ${ }^{[26]}$ in 1967. Our unit and others have reported favorable results using this technique. ${ }^{[27-30]}$ Therefore, we recommend this procedure when the distal portion of the severed nerve is absent or irreparable. The neuroma and proximal nerve are carefully dissected free of the surrounding tissues for a distance that will allow relocation into a local muscle or bone without tension [Figure 2]. The neuroma is resected and the site for relocation determined in an area free of scar tissue or any potential compressive forces. A small 

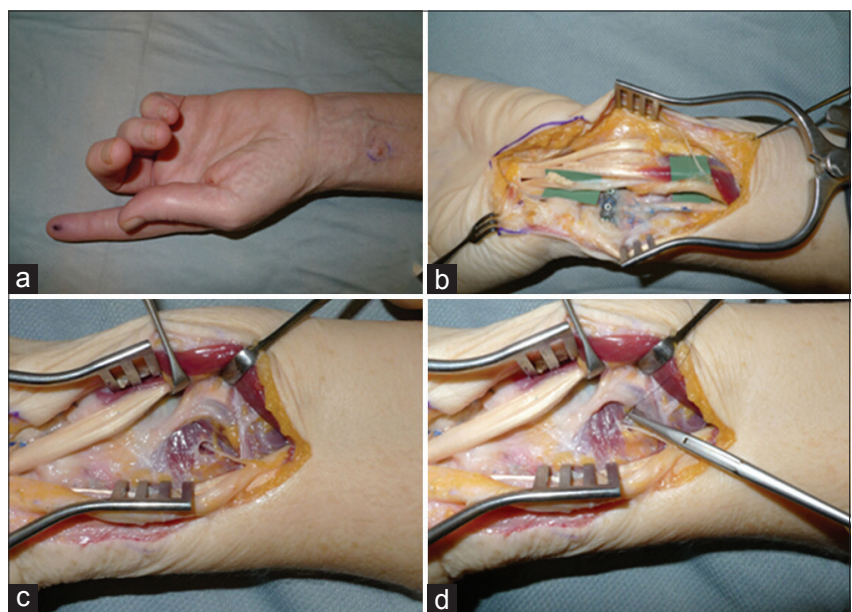

Figure 2: Technique of palmar cutaneous nerve relocation to pronator quadratus. (a) Preoperative skin marking shows neuroma of the palmar cutaneous branch of the median nerve; (b) dissection of palmar cutaneous nerve to origin from median nerve; (c) nerve relocated into muscle; (d) suture securing epineurium to epimysium

tunnel is dissected in the muscle, and the nerve is buried without tension. A single absorbable suture between the epineurium and epimysium holds the nerve in place. For placement into bone, a cortical hole is drilled obliquely to a size slightly larger than the nerve diameter. The nerve is relocated into this hole, and a single suture holds the epineurium to the adjacent periosteum [Figure 3]. It is important not to choose a site just distal to a joint where mobilization is likely to put strain on the nerve. It is also crucial to ensure there are no kinks or tension on the nerve and that it does not angle acutely on entering the bone. Our primary preferences for nerve relocation are as follows: (1) superficial radial nerve to the undersurface of brachioradialis or into radius; (2) palmar cutaneous branch of median nerve to pronator quadrates; (3) dorsal branch of ulnar nerve to pronator quadrates; (4) lateral cutaneous nerve of the forearm to pronator quadrates; (5) digital nerves at or distal to distal interphalangeal joint to the proximal phalanx; and (6) digital nerves proximal the distal interphalangeal joint to the metacarpal shaft.

\section{SURGERY FOR NEUROMAS-IN- CONTINUITY}

There is an even greater debate in the management of in-continuity neuromas. The treatment options fall into the following broad categories: (a) neurolysis alone, (b) nerve wrapping, (c) neuroma resection and reconstruction, and (d) neuroma resection and relocation.

\section{Neurolysis alone}

Preservation of functional sensitivity is vital for nerves such as the median and ulnar nerves. In these situations, neurolysis alone or nerve wrapping usually maintains the integrity of the intact axonal tissue. External neurolysis theoretically restores movement, thereby, preventing further scar adherence to the nerve, a suggested trigger for pain. ${ }^{[31,32]}$ A study of neurolysis alone in upper trunk brachial plexus neuroma-in-continuity revealed a functional improvement following neurolysis alone in cases where there was more

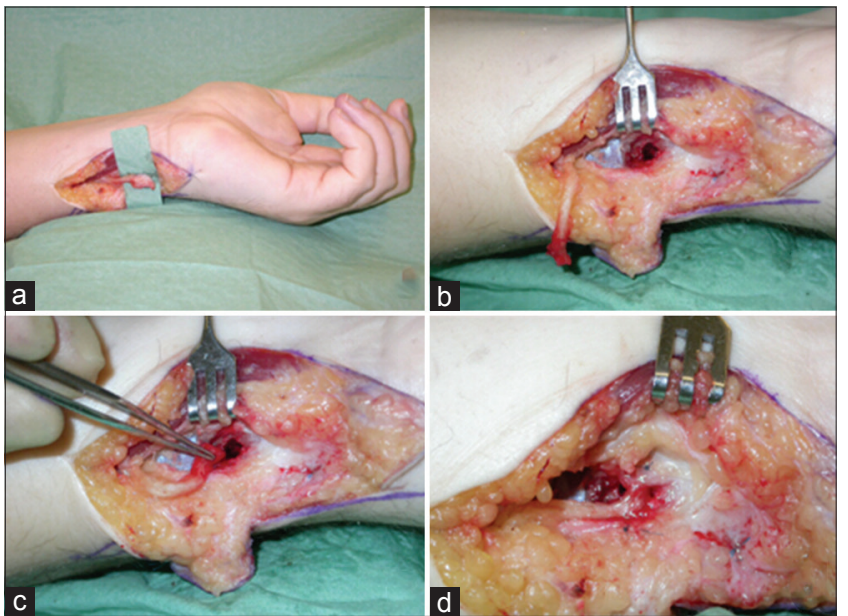

Figure 3: Technique of relocation of dorsal branch of ulnar nerve into ulna. (a) End neuroma of dorsal branch of ulnar nerve; (b) nerve dissected proximally; (c) nerve end can be placed in the ostium in distal ulna without tension; (d) epineurium is sutured to the periosteum to prevent displacement of nerve end

than $50 \%$ conduction demonstrated intraoperatively across the nerve. ${ }^{[3]}$ Opponents of neurolysis alone, however, warn of the risks of segmental revascularization and significant scar formation. ${ }^{[34]}$ This has led to the development of techniques designed to prevent recurrent scarring such as wrapping the nerve in a variety of protective substances.

\section{Nerve wrapping}

First described by Masear et al., ${ }^{[35]}$ vein wrapping ${ }^{[36]}$ has been reported as a successful technique in the management of both refractory cubital and carpal tunnel syndromes. Initially, glutaraldehyde-preserved allograft was used but has since been shown to cause increased scarring and adherence compared to autograft vein. ${ }^{[37]}$ Our unit has not had success with either technique and our limited experience of re-exploration in these cases the nerve was found to be tethered at both the proximal and distal sites on entry and exit of the vein graft. In general, we prefer to use vascularized fascia to wrap nerves. The largest series of vein wrapping to date has been reported by Kokkalis et al. ${ }^{[38]}$ who performed the procedure on seventeen patients for recalcitrant ulnar nerve compression at the elbow. Although they reported a significant reduction in symptoms in most of the patients, pain was not abolished in any single case.

For neuromas involving the critical ulnar and median nerves at the wrist or forearm, it has been our practice to use local fascial flaps to wrap the nerve, occasionally incorporating overlying skin and fat. Our unit has previously presented results of the analysis of 14 cases of neurolysis and fascial wrapping for nerves-in-continuity of the distal forearm or wrist. ${ }^{[39]}$ There was a complete resolution of pain in 8 of the 14 patients, and 2 more patients had only mild pain at 6 month follow-up. This technique was also used for the branches of the median and ulnar nerves to the palm and digits in an effort to preserve distal sensation, using division and relocation as a secondary procedure in the case of failure. We have found that there is little functional loss with the relocation of these nerves and have had greater success in abolishing pain with this technique. 


\section{Neuroma resection and reconstruction}

With a neuroma-in-continuity, there is an option to resect the neuroma and reconstruct the nerve. Again the same factors as mentioned previously will be considered (the functional importance of the nerve, the patient's desires, occupation, age). For noncritical nerves, we prefer to relocate the nerve as any loss of the remaining function is well-compensated for by relief of pain.

\section{Neuroma resection and relocation}

As discussed above, we now routinely relocate painful nerves as a primary procedure. Although yet to be published, our unit recently reviewed outcomes for relocation in this subset of patients who nerves were determined clinically or intraoperatively to be intact, that is, neuromas-in-continuity or tethered in surrounding scar tissue. Pain completely resolved in 21 of 23 patients. In the others pain reduced significantly in severity. Just 2 patients experienced mild pain at the site of relocation. The technique of relocation is the same as that for terminal neuromas as described previously.

\section{FUTURE DIRECTIONS}

Our treatment of choice in cases of neuromas involving the median and ulnar nerves refractory to nonsurgical means is neurolysis and wrapping the critical nerve in local vascularized fascia. It is usually easy to raise an adequate sized flap for this purpose based on the ulnar or radial arteries in the previously unscarred forearm. However, following multiple procedures the local tissue may be of substandard quality. Del Pinal et al. ${ }^{[40]}$ have reported the use of free vascularized adipofascial flaps in scarred beds in the forearm and hand to improve tendon gliding. The technique of free tissue transfer has been described previously to address scarred nerve beds of the brachial plexus. ${ }^{[41,42]}$ We are not aware of its application at more distal sites, and it is an avenue for future development.

Free fat grafting is one of the new ways to treat neuromas. ${ }^{[43]}$ This technique is minimally invasive and can be repeated. It has been shown to be valuable in treating Dupuytren's contracture and Raynaud's disease. Currently, we have no experience of this technique. We believe that there is a greater benefit from transferring vascularized fat attached to a fascial flap as it avoids the risk of fat necrosis seen with transferring aspirated fat.

Recently, there has been an introduction of biological and synthetic polymers to the field of nerve reconstruction. Excellent outcomes in terms of sensory recovery have been demonstrated using some of these materials as alternatives to autologous nerve grafts. ${ }^{[44,45]}$ The limitations include the length of the defect that can be treated (which is not longer than $2 \mathrm{~cm}$ ). The importance of the alignment in nerve guide conduits has been recently revealed, and the designers of the conduits are taking this into account. ${ }^{[46]}$ Furthermore studies of Schwann cell-seeded biodegradable poly(d, l-lactic acid) conduits demonstrated additional trophic and physical support, improving recovery. ${ }^{[47]}$

\section{CONCLUSION}

Pain following traumatic peripheral nerve injury falls into the category of neuropathic pain as defined by the international association for the study of pain yet these injuries are not frequently included in the neuropathic pain literature. Although there are several epidemiological and quality of life studies relating to neuropathic pain, very few of these studies include peripheral nerve injuries. ${ }^{[48-51]}$ This lack of knowledge was highlighted in a review by Novak and Katz. ${ }^{[52]}$ They concluded that there is very little information on incidence and severity of neuropathic pain, the associated disability, impact on quality of life or health status of patients with traumatic peripheral nerve injuries. Most studies report only on the physical impairment related to motor and/or sensory recovery. There are, however, a large number of reports detailing intervention outcomes that shows the enormity of the problem and the lack of a single reliable solution.

Determining the cause of postinjury pain is the key to success in treatment and can often be achieved by a thorough clinical evaluation alone. Injury of a sensory nerve may result in altered sensation or anesthesia in the distribution of the nerve. Unless accurate coaptation of the epineurium is achieved, neuroma formation is inevitable but is not in the majority of cases painful. The two main processes believed to be responsible for neuroma-mediated pain are local persistent mechanical or chemical stimulation of the nerve ending and central stimulation of dorsal ganglion, spinal cord and central nervous system pathways. This understanding has led to the development of techniques to wrap the nerve or move the nerve to a site where it is less irritated.

A multitude of surgical techniques has been described in cases that fail conservative measures. Indeed, such a wide array of treatments suggests that there is no single way of completely and effectively managing peripheral neuromas with surgery. There are some general principles, which guide the surgical choice. If the nerve injury is recent, we explore immediately with the aim to primarily repair the nerve if possible or resect the injury and reconstruct with autologous nerve grafts. In the case of established neuromas-in continuity, where the nerve provides a distal critical function such as in the case of the median or ulnar nerves, every effort is made to preserve the functional elements. Our procedure of choice is neurolysis and wrapping the nerve in a local vascularized fascial flap. When the smaller cutaneous nerves or digital nerves are involved, we generally opt for relocation to a site determined by the nerve injured and the level of injury. End-neuromas of these smaller cutaneous nerves are managed similarly with relocation to local muscle or bone.

\section{REFERENCES}

I. Cruccu G, Anand P, Attal N, Garcia-Larrea L, Haanpää M, Jørum E, Serra J, Jensen TS. EFNS guidelines on neuropathic pain assessment. Eur J Neurol 2004; I I:I53-62.

2. Loeser JD, Treede RD. The Kyoto protocol of IASP basic pain terminology. Pain 2008;137:473-7. 
3. Merskey H, Bogduk N. Classification of Chronic Pain: descriptions of Chronic Pain Syndromes and Definitions of Pain Terms. 2nd ed. Seattle: IASP Press; 1994. p. 212.

4. Sunderland S. Nerve Injuries and Their Repair: a Critical Appraisal. Melbourne: Chuchill Livingstone; 1991. p. 186-7.

5. Torebjörk E. Human microneurography and intraneural microstimulation in the study of neuropathic pain. Muscle Nerve 1993; 16:1063-5.

6. Ochoa JL. The human sensory unit and pain: newconcepts, syndromes and tests. Muscle Nerve 1993;16:1009-16.

7. Bonney G. latropathic. In: Birch R, Bonney G, Parry CB editors. Surgical Disorders of the Peripheral Nerves. London: Churchill Livingstone; 1998. p. 293-333.

8. Tupper JW, Booth DM. Treatment of painful neuromas of sensory nerves in the hand: a comparison of traditional and newer methods. J Hand Surg Am 1976;: : 144-51.

9. Sai S, Fujii K, Hiranuma K, Sato T, Nemoto T. Preoperative ampiroxicam reduces postoperative pain after hand surgery. J Hand Surg Br 200 I;26:377-9.

10. Lee J, Nandi P. Early aggressive treatment improves prognosis in complex regional pain syndrome. Practitioner 20I I;255:23-6,3.

II. Baron R. Neuropathic pain: a clinical perspective. Handb Exp Pharmacol 2009;(194):3-30.

12. Moore RA, Wiffen PJ, Derry S, Toelle T, Rice AS. Gabapentin for chronic neuropathic pain and fibromyalgia in adults. Cochrane Database Syst Rev 2014:4:CD007938.

13. Wiffen PJ, Derry S, Moore RA, Kalso EA. Carbamazepine for chronic neuropathic pain and fibromyalgia in adults. Cochrane Database Syst Rev 2014:4:CD00545।.

14. Rowbotham MC. Pharmacologic management of complex regional pain syndrome. Clin J Pain 2006;22:425-9.

15. Siddiqui A, Laing T, Poel J, Want M, Sood M. Management of Nerve Pain in Upper Limb Using External Neuromodulator in an Outpatient Setting. Proceedings of the I2th Congress of ESPRAS; 2014 Jul 6-I I; Edinburgh, UK. Bologna: Medimond Publishers; 2014.

16. Guse DM, Moran SL. Outcomes of the surgical treatment of peripheral neuromas of the hand and forearm: a 25-year comparative outcome study. Ann Plast Surg 2013;71:654-8.

17. Zeltser R, Beilin B, Zaslansky R, Seltzer Z. Comparison of autotomy behavior induced in rats by various clinically-usedneurectomy methods. Pain 2000;89:19-24.

18. Kayikçioğlu A, Karamürsel S, Ağaoğlu G, Sargon MF, Keçik A. A new epineural nerve repair technique: oblique nerve coaptation. Ann Plast Surg 1999;43:506-12.

19. Marcol W, Kotulska K, Larysz-Brysz M, Bierzyńska-Macyszyn G, Wlaszczuk P, Lewin-Kowalik J. Prevention of painful neuromas by oblique transection of peripheral nerves. J Neurosurg 2006; 104:285-9.

20. Martini A, Fromm B. A new operation for the prevention and treatment of amputation neuromas. J Bone Joint Surg Br 1989;71:379-82.

21. Dahlin LB, Lundborg G. Use of tubes in peripheral nerve repair. Neurosurg Clin N Am 2001;12:341-52.

22. Low CK, Chew SH, Song IC, Ng TH, Low YP. End-to-side anastomosis of transected nerves to prevent neuroma formation. Clin Orthop Relat Res 1999;(369):327-32.

23. Al-Qattan MM. Prevention and treatment of painful neuromas of the superficial radial nerve by the end-to-side nerve repair concept: an experimental study and preliminary clinical experience. Microsurgery 2000;20:99-104.

24. Lagarrigue J, Chavoin JP, Belahouari L, Scavazza R. Treatment of painful neuroma by a nerve anastomosis, "neuronal trap" loop. Neurochirurgie 1982;28:9|-2.

25. Kon M, Bloem JJ. The treatment of amputation neuromas in fingers with a centrocentral nerve union. Ann Plast Surg 1987;18:506-10.

26. Herndon JH, Eaton RG, Littler JW. Management of painful neuromas in the hand. Bone Joint Surg Am 1976;58:369-73.

27. Sood MK, Elliot $D$. Treatment of painful neuromas of the hand by relocation into the pronator quadrates muscle. J Hand Surg Br 1998;23:214-9.

28. Hazari A, Elliot D. Treatment of end-neuromas, neuromas-in-continuity and scarred nerves of the digits by proximal relocation. J Hand Surg $\mathrm{Br}$ 2004:29:338-50.

29. Dellon AL, Aszmann OC. Treatment of superficial and deep peroneal neuromas by resection and translocation of the nerves into the anterolateral compartment. Foot Ankle Int 1998; 19:300-3.
30. Otfinowski J, Pawelec A, Kaluza J. Implantation of peripheral neural stump into muscle and its effect on the development of posttraumatic neuroma. Pol J Pathol 1994;45: 195-202.

31. Millesi H, Zöch G, Rath T. The gliding apparatus of peripheral nerve and its clinical significance. Ann Hand Surg 1990;9:87-97.

32. Wilgis EF, Murphy R. The significance of longitudinal excursion in peripheral nerves. Hand Clin 1986;2:76I-6.

33. Andrisevic E, Taniguchi M, Partington MD, Agel J, Van Heest AE. Neurolysis alone as the treatment for neuroma-in-continuity with more than $50 \%$ conduction in infants with upper trunk brachial plexus birth palsy. J Neurosurg Pediatr 2014;13:229-37.

34. Jones NF, Shaw WW, Katz RG. Circumferential wrapping of a flap around a scarred peripheral nerve for salvage of end-stage traction neuritis. J Hand Surg Am 1997;22:527-35.

35. Masear VR, Colgin $S$. The treatment of epineural scarring with allograft vein wrapping. Hand Clin 1996; 12:773-9.

36. Varitimidis SE, Riano F, Vardakas DG, Sotereanos DG. Recurrent compressive neuropathy of the median nerve at the wrist: treatment with autogenous saphenous vein wrapping. J Hand Surg $\mathrm{Br}$ 2000;25:27I-5.

37. Ruch DS, Spinner RM, Koman LA, Challa VR, O'Farrell D, Levin S. The histologic effect of barrier vein wrapping of peripheral nerves. J Reconstr Microsurg 1996;|2:29|-5.

38. Kokkalis ZT, Jain S, Sotereanos DG. Vein wrapping at cubital tunnel for ulnar nerve problems. J Shoulder Elbow Surg 2010;19:91-7.

39. Elliot D, Lloyd M, Hazari A, Sauerland S, Anand P. Relief of the pain of neuromas in continuity and scarred median and ulnar nerves in the distal forearm and wrist by neurolysis, wrapping in vascularized forearm fascial flaps and adjunctive procedures. J Hand Surg Eur Vol 2010;35:575-82.

40. Del Pinal F, Moraleda E, de Piero GH, Ruas JS. Outcomes of free adipofascial flaps combined with tenolysis in scarred beds.J Hand Surg Am 2014;39:269-79.

41. Brunelli G. Neurolysis and freemicrovascularomentum transfer in the treatment of postactinic palsies of the brachial plexus. Int Surg 1980;65:5 I5-9.

42. Brunelli GA, Brunelli F, Di Rosa F. Neurolized nerve padding in actinic lesions: omentum versus muscle use. An experimental study. Microsurgery 1988;9:177-80.

43. Vaienti L, Gazzola R, Villani F, Parodi PC. Perineuralfat grafting in the treatment of painful neuromas. Tech Hand Up Extrem Surg 20I2;16:52-5.

44. Lohmeyer JA, Kern Y, Schmauss D, Paprottka F, Stang F, Siemers F, Mailaender P, Machens HG. Prospective clinical study on digital nerve repair with collagen nerve conduits and review of literature. J Reconstr Microsurg 20I4;30:227-34.

45. Taras JS, Jacoby SM, Lincoski CJ. Reconstruction of digital nerves with collagen conduits. J Hand Surg Am 201 1;36: I441-6.

46. Li J, McNally H, Shi R. Enhanced neurite alignment on micro-patterned poly-L-lactic acid films. J Biomed Mater Res Part A 2008;87:392-404.

47. Rutkowski GE, Miller CA, Jeftinija S, Mallapragada SK. Synergistic effects of micropatterned biodegradable conduits and Schwann cells on sciatic nerve regeneration. J Neural Eng 2004;1:151-7.

48. Jensen MP, Chodroff MJ, Dworkin RH. The impact of neuropathic pain on health-related quality of life: review and implications. Neurology 2007;68: II 178-82.

49. Meyer-Rosberg K, Kvarnström A, Kinnman E, Gordh T, Nordfors LO, Kistofferson A. Peripheral neuropathic pain: a multidimensional burden for patients. Eur J Pain 2001;5:379-89.

50. Meyer-Rosberg K, Burckhardt CS, Huizar K, Kvarnstrom A, Nordfors LO, Kistofferson A. A comparison of the SF-36 and Nottingham Health Profile in patients with chronic neuropathic pain. Eur J Pain 2001;5:39I-403.

5I. Toth C, Lander J, Wiebe S. The prevalence and impact of chronic pain with neuropathic pain symptoms in the general population. Pain Med 2009; 10:918-29.

52. Novak $C B, K a t z J$. Neuropathic pain in patients with upper-extremity nerve injury. Physiother Can 20 10;62:190-201.

How to cite this article: Laing $T$, Siddiqui $A$, Sood $M$. The management of neuropathic pain from neuromas in the upper limb: surgical techniques and future directions. Plast Aesthet Res 2015;2:165-70.

Source of Support: Nil, Conflict of Interest: None declared.

Received: 10-02-2015; Accepted: 13-05-2015 